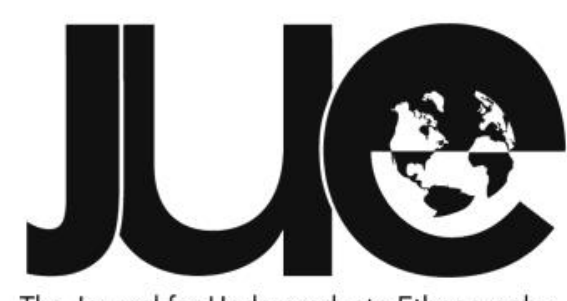

\title{
From Maggots to Millions: Biomimicking the Fly to Feed Humanity from its Waste in the 21st Century
}

\author{
Charlie Drew \\ Durham University, charlie@charliedrew.com
}

\section{ABSTRACT}

'QUIET PLEASE: Flies are breeding'... reads the sign displayed on the factory breeding room. A female black soldier fly (BSF) is laying around 1500 tiny white eggs onto an industrially designed grid. Over 21 days, one kilogram of her eggs will hatch into eight tonnes of larvae, which will initiate a natural process of waste nutrient recycling as they feed on containers of organic consumer waste that would otherwise go to landfill. In a factory in one of Cape Town's rapidly developing postapartheid townships, larvae are thus recycling some 250 tonnes of 'pre' and 'post' consumer waste every day, transforming negative value waste products into highly valuable insect protein, an alternative to fishmeal - an unsustainably ocean sourced protein. Ethnographic research in this factory explored this biomimically inspired innovation, which uses nature's purification agents - fly larvae - to revalorise a potentially harmful waste product into a critically important food source for the 21st Century. This paper argues that these industrially designed insect farms produce specific technologies and violent acts of reproductive enclosure. By incorporating debates about the role of naturally inspired solutions that use biological labour to accumulate value, it makes plain the ethical implications that emerge from mimicking and enclosing nature in this way. It contends that the ambition of the discipline of biomimicry to reunite human economies with natural ecologies is overshadowed by the logics of capitalism. While the outcomes of biomimicry may indeed be ecologically sustainable, capitalism's drive to privatise and profit from the knowledge and labour of nonhuman life means not only controlling animals and their products, but also controlling the processes of life through a constellation of scientific, bureaucratic and legal techniques.

Keywords: Biomimicry, consumer waste, Black Soldier Fly (BSF), nonhuman life, enclosure, violence. 
struggle through some beef stew as I sit down for the first lunch break of my research. I manage half of it before heading out into the factory courtyard to empty my leftovers into the nearest food bin. I don't walk far to find industrial silos of consumer waste. After all, I am in the right place.

My leftovers have just joined the first step in a highly innovative process of waste nutrient recycling at the world's largest insect factory in one of Cape Town's rapidly developing postapartheid townships. It will join the 250 tonnes of mixed waste that flow through this factory each day. This represents a small part of the 1.3 billion tonnes of food waste the world's population sends to landfills daily (FAO, 2016). Whilst one third of human food production is discarded, we face growing demands for protein production threatening to decimate the finite resources of our planet. We need a better solution and perhaps we can learn to look towards nature for it.

Biomimicry involves an act of 'taking nature's lead', to engineer and industrialise production processes that occur naturally, to overturn the tenets of waste production (Johnson, 2010). As I follow the journey of my leftovers through a complex network of industrially engineered processes, I draw upon my ethnographic observations of working in an environment that tries to reproduce nature under industrial conditions. I evaluate the forces, relationships, actors and networks that enable this process to function. Through my interviews and conversations with the factory's pioneers, scientists and investors, I expose and critique this form of biomimicry. Where permitted, I incorporate analysis of factory designs, waste processing data and scientific knowledge to contextualise the processes at work. Some of

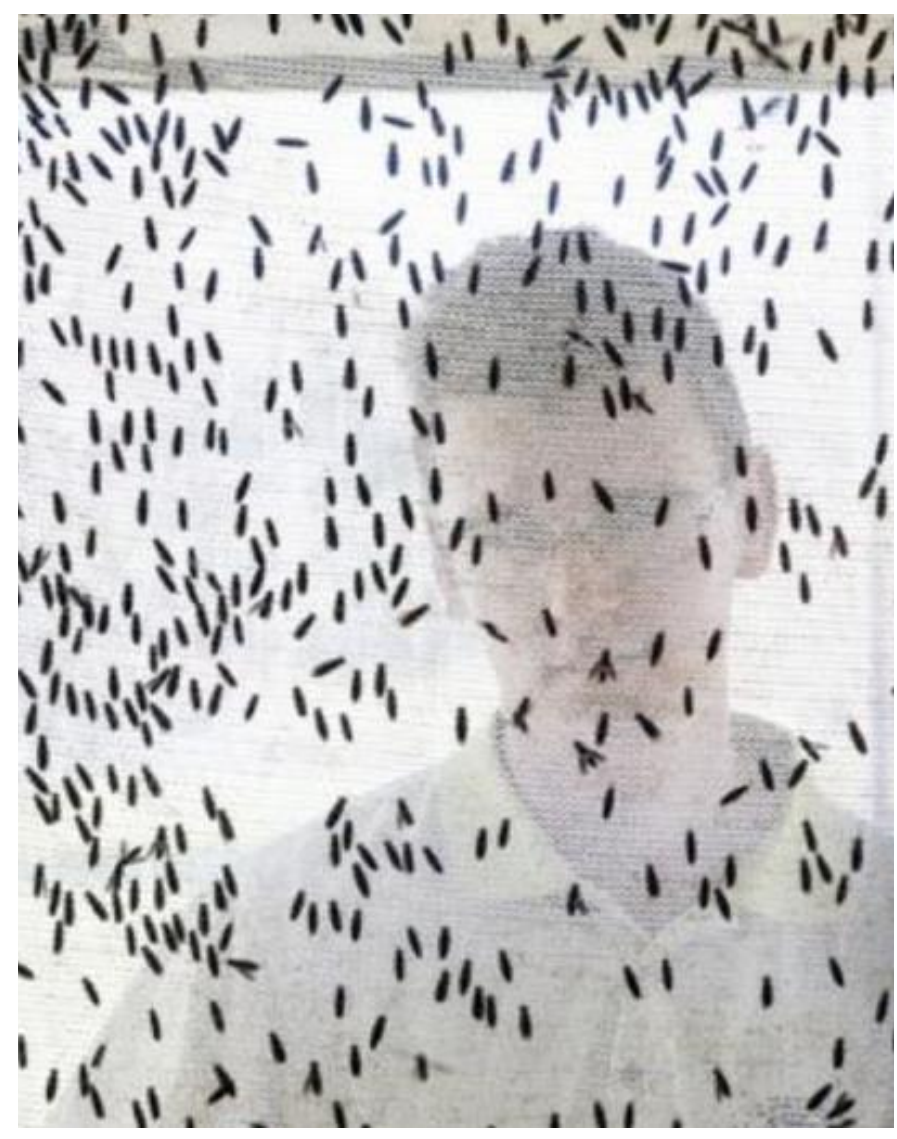

Figure 1: Investigating the breeding colony at the world's first insect nutrient recycling plant. Photo: AgriProtein

these processes are summarised in figure 2 below.

This paper investigates the contested discourses about how nature is produced through the temporal, technological and spatial enclosures of the fly factory. It takes up the issue of the entanglement of nature and capitalism, through a critical political economy analysis of market enclosures, whilst exploring the key relationships involved in these captures. It argues that due to its capitalist mode of production, biomimicry does not simply harness, but rather alters and exploits, the evolutionarily derived knowledges of black soldier flies. It casts a critical lens on the forms of entanglement that are produced in an insect factory by putting nonhuman life to work, and argues that this reveals how biomimicry can be misrepresented as a reunification of human and natural processes, at the expense of emphasizing the primarily coercive conditions of capitalism. This continues to place natural processes in a secondary position to human ambitions, which results in the enactment of violence against nonhuman labourers. 


\section{Positioning the Research: Biomimicry and Enclosure}

This article argues that the interaction of biomimicry, nonhuman labour and enclosure produce a specific and distinctive set of temporal, technological and spatial enclosures in the fly factory. It draws out the distinctions between traditional forms of biomimicry, which rely upon the knowledge embodied with natural ecosystems, and a movement in biotechnology that harnesses organisms as nonhuman agents. This discrepancy develops through the analysis of enclosure, an ongoing process that enables the expansion of capital into the natural world (Braun 2008).

The building blocks of biomimicry lie in a discipline that seeks to repair a nature-society divide, in order to reverse humankind's "unreceptive relationship" with the natural world (Benyus 1997, 287). A number of scholars argue that humanity has forgotten its connection with nature and, as a result, nature is cast as an "abandoned realm" set off from the 'human' (Braun 2008, 667; Smith 1984). The environment has become an abstract sphere, rendered as a mere "receptacle" of natural resources to be exploited for human advance (Braun 2008, 668). The underlying promise of biomimicry is to re-establish our intimacy with the natural world, emulating nature's knowledge and ingenuity to redesign sustainable production systems. Building on nature's "four-billion-year head start," it reimagines ecologically sustainable modes of production that do not seek to "tame or override" nature (Khan 2017, 7). It attempts to reimagine anthropocentric production methods

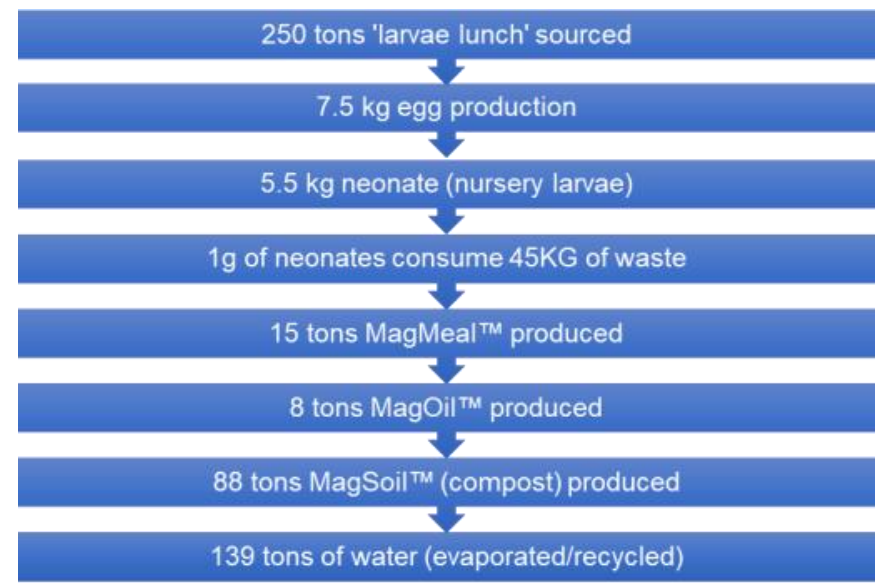

Figure 2: The phases of the insect nutrient recycling process. by learning how nature succeeds, as it recognises the "existence proof in naturally occurring physiology" (Johnson 2010, 179).

\section{Harnessing a Nonhuman Workforce}

The use of nonhuman organisms as "active labourers within capitalist environments" extends exploitation into the natural realm and marks a departure from the ability to simply learn from nature (Perkins 2008, 1154). This "renders a new (a)symmetry of politics and power" over nonhuman life as a new workforce is conscripted (Perkins 2008, 1159). Under this vision, the world's 30 million species are considered a potential resource of nonhuman labour, expanding the geographies of capitalism as the initial biomimetic vision is left behind (McCarthy 2004; Johnson 2010).

There is a contentious politic around how this shift is affected. By ignoring the role of a nonhuman workforce within the emerging biomimicry discourse, the discipline risks reproducing the problem of making nature secondary and thereby enacting a form of violence upon it. In the analytical discussion that follows, I extend and explore the issue of violence through a specific case of 'biopiracy' that is contextualised by putting nonhuman life to work in the insect factory.

In subjecting new lifeforms to work, "biomimicry draws nonhuman participants into an ongoing process of enclosure" (Johnson and Goldstein 2015, 388). Enclosure can be understood as a capitalist technique and rationality, that appropriates natural processes from the commons as it extends the market apparatus to nonhuman life (Buitrago 2015). Enclosure exerts a "conscious imposition of power over nature" and has arisen as a byproduct of the capitalist accumulation system (De Angelis 2004, 77). Traditional forms of biomimicry that acknowledge nature's expertise might initially appear less exploitative. New forms of biomimicry enable capitalism to render biological work and knowledge as a resource to exploit.

Capitalism investigates the diverse forms of knowledge captured within nonhuman life and "reduces it into a divisible, isolatable field of potential intellectual property" that acts in service to primitive accumulation (Goldstein and Johnson 2015, 17). If scholars are to accept 
biomimicry's vision of a more sustainable future, they must also recognise the acquisitive power of capital's logic and its historic tendency to subsume natural processes (Braun 2008). These processes of biological enclosure "penetrate into the depths" of the organism, driven by capitalism's perpetual attempt to accumulate and privatise both the knowledge and labour of nonhuman life (Goldstein and Johnson 2015, 13). The enclosure of nature is not independent but can be understood as a force driven by a "hammer that smashes nature for the sake of capital" (De Angelis 2004, 78). Biomimicry allows us to theorise the changing sites and spaces of this fragmentation of nonhuman life.

These spaces have changed irrevocably throughout the history of enclosure and are now orientated towards the micro-commons, which are divided by new technologies that expand into the depths of organisms. These enclosures can represent the "commodification of ever smaller bits of biodiversity" that reach into cellular genomes and DNA (Katz 1998, 51). The efforts undertaken to privatise intellectual property no longer stop at the body of the organism, they extend to almost "impossible subjects of enclosure" (McCarthy 2004, 337). Biotechnology companies and agricultural corporations are seeking to patent and privatise "previously unknown aspects of nature" that include useful genetic traits and environmental conditions (McCarthy 2004, 330). This process of 'bio-prospecting', involves "corporate pirates scouring the natural world" for patentable genetic and environmental property (Smith 2007, 21). These corporations, labelled as "raiders of future nature" are creating new genetic commodities which are dissolving the boundaries between human and nonhuman nature (Smith 2007, 21). These continued attempts to identify and target new microsubjects of enclosure can be conceptualised through Goldstein's (2010) notion of 'terra economica'. A "persistent logic of expropriation" that envisions the whole earth as a produced nature that is "not-yet but potentially commodified" (Goldstein 2010, 372). Nature's fate is determined by what capital can see and what obscures that vision (Goldstein, 2010). Biomimicry can therefore be understood as a techno-scientific movement that opens up a further field of vision to capital and its processes of enclosure. This review has sought to draw attention to the specific issues of putting nonhuman life to work and the continuous character of enclosure that secures nonhuman labour. In some instances, these literatures pose a contrast to the work of traditional biomimicry and offer a context with which to read the empirical section of this research. This review has begun to anticipate and flag some of the concerns associated with emerging forms of biomimicry and how they might exacerbate the human-nature divide. In the following empirical work, I stitch these core conceptual bodies of work together and through the study of an insect factory - show how the concepts of biomimicry nonhuman work and enclosure interact.

\section{A 'Multi-Species' Ethnography}

The methodology constructed for this research sought to engage with a cross-section of the company's employees across all levels from the directors, scientists and factory workers to the insects themselves. The methodology aims to acknowledge the biomimical technologies that operate in the factory, whilst equally recognising the role of its nonhuman workforce. A multi-species ethnographic approach acknowledges the agency of organisms whose lives are entangled with humans and capitalism. This method is used to analyse how the livelihood of "organisms are shaped by political, economic and cultural forces" (Kirksey and Helmreich 2010, 544). I was attentive to the ways in which the fly coproduces the spaces it is enclosed in, through its rhythms of reproduction and consumption. I followed the BSF through the labyrinth of the insect factory, observing the workers who care for these insects, the entomologists who monitor their behaviour and the engineers who continually improve the technologies that enclose them. To construct my ethnographic research, I tracked my leftovers through the circuitry of the factory, analysing the interaction of human and nonhuman labour that is synchronised around the production process. Working with these insects in their cages, I observed their unique ability to transform waste and their methods of resistance. I became an active participant in each of these environments to gain a sense of the factory as a whole, all the way down to the level of the fly and its biological components. 


\section{Making Larvae Lunch}

Ticket number 323678 is printed at the weighbridge as the next inbound delivery of waste is electronically recorded. A dump truck from a fruit producer pulls up the ramp and weighs in nine and a half tonnes of pulp residue waste from high-end juice production. A sample of the waste is sent to the laboratory to ensure that the moisture and nutrient content profiles are within the agreed limits for this particular contract. Waste is obtained from a variety of sources including the canteens of large international banks, fast food chains and airlines that serve the city of Cape Town.

Waste is traditionally theorised as a postconsumer externality that represents "the political other of capitalist value", however, for Agriprotein it is an integral production resource (Gidwani and Reddy 2011, 1625). The company is continually scouring the market for low-cost, high protein and carbohydrate rich waste. This morning's inbound deliveries show that AgriProtein has spent a net $£ 140$ on sourcing 31 tons of waste from their contractors (see figure 3). For Darren, AgriProtein's feedstock manager (a pseudonym), this is a familiar trend. With the increasing demand for this commodity he expects that waste will become a marginal net cost for the first time in 2018.

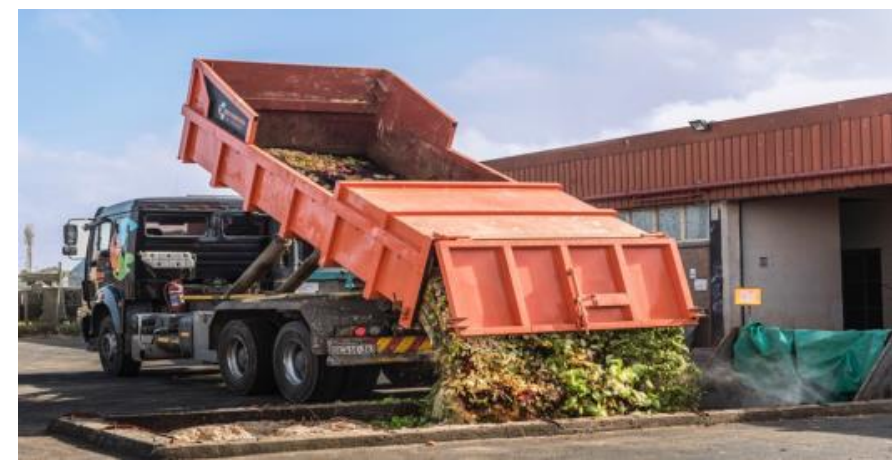

As a variety of organic waste streams are combined to feed a hungry insect colony, two divided ecology sets that are concerned with waste can be considered as being: "On the one side a way of life, that churns out growing quantities of waste and on the other, lives that live off this commodity detritus" (Gidwani and Reddy 2011, 1652). The ability to source waste from the urban ecology that produces it is a key determinant for the location and viability of a new factory. The insects who form part of the ecology that depend on the quality and continual availability of this commodity are producing a new economic geography of waste demand in the city of Cape Town. There is a logistical challenge in securing waste seven days a week, as its generating industries typically function around a five-day working week. This complex interaction of human and nonhuman market economics requires AgriProtein's factories to be located close to the ecology that produces waste. AgriProtein's ability to construct factories within the innercity is due to the process of waste cleansing and purification that takes place in the insect factory. Their factory model seeks to revolutionise the spaces where waste can be repurposed, bringing agricultural production in close proximity to the urban ecology that produces waste. The waste assessment results are positive for the fruit pulp and Agriprotein will receive a $£ 33$ gate fee for this load. For WastemMart, a municipal waste disposal contractor in the city of Cape Town, this represents a 30 per cent saving compared to the cost of landfill fees. The truck is given the all clear and it unloads the organic waste into a processing pit before the first stage of production begins.

As Ricardo's team of workers start up the conveyor belt, the industrial revalorisation of waste begins. Revalorisation refers to a process where waste is transformed from a by-product with negative value to a new form of material with considerable economic value. An insect diet manager calculates the nutrient requirements for the factory against the daily waste intake. The morning delivery, including my leftover lunch, is mixed into batches which are then loaded onto the conveyor belt. A team of factory pickers manually remove inorganic material from the line before the waste is shredded into a precise particle size for the larvae to process efficiently. Much of social science's engagement with waste "remains staunchly immaterial" yet waste is "intrinsically and profoundly a matter of materiality" (Gregson and Crang 2010, 1026). In acknowledging the materiality of waste, this commodity can be understood as a product with limitless possibilities for revalorisation

Figure 3: A dump truck empties organic food waste into the processing pit. Photo: AgriProtein. 
(Gregson and Crang, 2010). Organic waste from the shredder is pumped into a mixing tank where its consistency is optimised before being delivered to two 30,000 litre storage silos, ready to become the next batch of larvae lunch.

\section{Biomimicking the Environment}

Dawn breaks over Cape Town, signalling the start of the next shift in the insect breeding room, a team of five factory workers and I draw in our last breaths of dry cold air before we step through the layers of PVC strip curtains, entering a warm, humid bio-secure environment where 416 insect rearing cages are stacked two high, eight abreast and twentysix rows deep. I discover that it is permanently dawn in the breeding room; a state that is reproduced through arrays of LED bulbs. The artificial blue light they emit mimics the specific wavelength of light that is refracted over the horizon during the dawn in the summer, stimulating the mating of this American insect species. The replication of this wavelength throughout the fly's breeding cycle increases egg laying efficiency four-fold in comparison to natural light cycles. This patented light cycle represents an integral piece of intellectual property that drives production efficiency in the breeding room.

Biomimicry is guided by capturing the
knowledge and practices embodied in
ecological systems, redesigning and amplifying natural processes to produce conditions conducive to life (Goldstein and Johnson 2015). By analysing the micro-spaces where the BSF lay in the wild, AgriProtein's scientific team discovered that their physiological strategy is to lay eggs next to a food source rather than the majority of insects who lay their eggs within it. This crucial and unique difference makes the BSF one of the very few insect species conducive to industrial mimicry. "If they were a primary species in the decomposition chain AgriProtein wouldn't be here today" remarks a process design engineer. "It would make industrial production impossible; you cannot separate eggs from the food source within the breeding cages and prevent the spread of disease". BSF do not spread pathogens because they do not feed during adulthood, it is only their offspring (larvae) that organically decompose waste. Most other fly species that feed during adulthood pick up and distribute bacteria. This crucial difference allows the factory to separate the breeding colony (figure 1) in a bio-secure environment away from the waste processing plant.

Our first task of the morning is servicing the cages. In 80 per cent humidity, Loisa and I navigate the tight aisles, replenishing them with "larvae cologne" (figure 4). This insect perfume emanates from a small gauze tray soaked in a specially created bacterial culture. The tray is attached to a small fan unit that diffuses insect perfume into the laying grids to mimic the availability of a decaying food source. This simple innovation stimulates insects to lay eggs in the belief there is a decomposing waste on which their offspring will survive, without placing a potentially contaminated food source in their cages.

I collect and place the new egg laying grids at one edge of the cage, away from the fluorescent light. When the female insect is ready to lay, she seeks a secure area to oviposit. If she feels with her ovipositor that the distance between the two points is too wide, she will not lay in the belief that her offspring will be exposed. Small curved indentations in the egg laying grids mirror the crevices in which a female fly would lay in the wild. These grids allow egg laying to be accurately controlled within the cages, as the insects are encouraged to lay in perfectly aligned micro-spaces. Here, industrial design is central to the mass production and rearing of insects. Before these intricately engineered processes of biomimicry were introduced, insects displayed considerable resistance to most forms of enclosure. By organising laying around certain spaces of the cage, egg collection efficiency can be maximised in micro-spaces that are pared down into individual elements of the production process. Stages of the insect's lifecycle are fragmented and subsequently aligned into a highly efficient form of production. This nonhuman body is being transformed into an organised form of labour similar to that of the factory labourer, whose conduct is constantly modulated to obtain the maximum effects of utility from the factory floor (Foucault, 1977). 


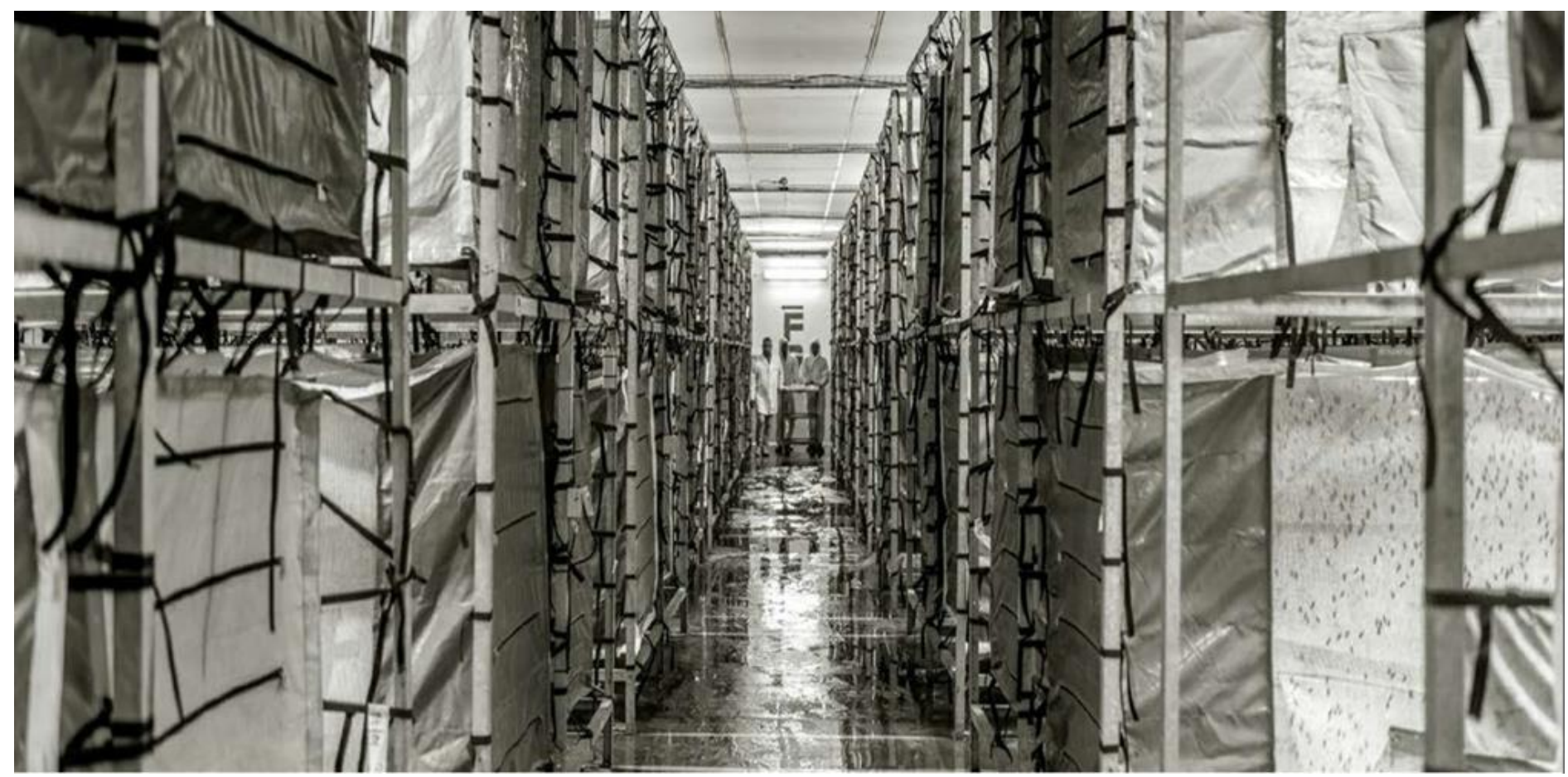

Figure 4: Navigating the tight aisles between cages to service them with 'larvae cologne'. Photo: AgriProtein

When the factory managers and scientists try to enhance natural efficiencies, they turn towards an industrial model of production. Whilst the mathematical spaces of the insect cages mimic nature, they are also producing an anticipatory infrastructure for enclosure. At the moment in which nonhuman life is acknowledged as a source of inspiration, "it is simultaneously circumscribed" as capitalism seeks to confine nature to a finite space of industrial production (Braun 2008, 668). Encircling nature in this way is not random, it depends upon a team of entomologists and industrial engineers who mathematically generate spaces that are conducive to mass insect production. This forges a relationship between economic forces and nonhuman nature that is no longer dialectic, but rather one where capitalist forces act in opposition to a recalcitrant form of nonhuman life (Harvey and Braun 1996). The scientific reasoning that is used to redesign and amplify natural process in the insect factory is premised upon minimising the resistance of nonhuman life rather than simply emulating nature's processes. Insects do everything in their power to resist enclosure, and constantly seek ways of escaping the spaces in which they are confined. This represents a move beyond biomimicry, towards a mimicry that acts in constant service to capital production rather than nature itself.
The company strives to increase survivability across all stages of the insect production process. Whilst drawing upon natural inspiration to design key industrial processes they employ a team of 41 entomologists, researchers and production engineers. The team are constantly searching for further natural variables to mimic and enhance. To process 250 tonnes of waste per day, $7.5 \mathrm{~kg}$ of daily egg production is required, targets which the biology managers are intent on achieving.

'Lecking' spaces have been incorporated into cage design structures to allow males to territorially display for females, which reduces overcrowding and encourages egg laying. This constant reorganisation and enclosure of the insects' reproductive space represents yet another strategy that drives the accumulation of capital in the factory. For Marx (DyerWitheford, 2002) the production of surplus value is conditional upon harnessing human labour power; whilst he does not extend this notion to nonhumans, there is an analogous set of issues at work in the insect factory. There are concerns as to whether the lifeform should earn a 'living wage' as this reproductive workforce is 'bioutilised' in the factory (Fisch 2017). Value is created and harnessed through the reproductive and waste processing capacity of the fly as these unpaid organisms are conscripted. The reorganisation of nature, 
impelled by the forces of capital, captures the work of the insect in the factory as these enclosures penetrate into the depth of the reproductive space of the fly (Goldstein and Johnson 2015).

\section{Putting Nonhuman Life to Work}

Inside the factory's breeding cages, the world's largest nonhuman workforce (by head count) have been hard at work, laying their microscopic white eggs onto 3076 of these laying grids (AgriProtein 2017). I set about collecting and replacing them, monitoring cage conditions whilst cleaning these luxury mating spaces - a relentless process in the 28-degree (Celsius) heat. As I collect the last of our grids the team assemble around the weighing station; the laying looks particularly encouraging this morning and over 170 million eggs have been collected. Over the last four hours I have performed a rigorous and monotonous act of replacing, ordering and counting egg grids. The ordered and formulaic process of managing an insect colony is unlike the process of a fly laying its eggs on a compost heap, which might seem messy in comparison. Nature in the fly factory is subjected to a host of novel reorganisations driven by the desire to eliminate what humans consider to be 'natural inefficiencies.'

The factory depicts a stark contrast to the vision envisaged by Benyus, the architect of the biomimicry movement. For Benyus (1997), biomimicry represents an opportunity to reimagine the exploitative relationship between human life and the natural world. By drawing upon nature as a mentor, it seeks to reverse understandings of the natural world as an unlimited opportunity for extraction, and instead relies upon nature's expertise as a conduit to more sustainable production processes. Whilst the majority of the biomimicry literature is suggestive of imitating nature and its natural design knowledge "none of the prominent ideas in biomimicry are using organisms, rather the blueprints and recipes from those organisms" (Benyus 2005).

These organisms are mimicked and simultaneously captured as active labourers on the factory floor. Nature in the insect factory is a nonhuman agent that becomes entangled within a very specific logic of enclosure and capital accumulation (Jessop 2005). 8.4 billion insect bodies in one single factory are commodified for their labour power and utility in an industrial process of waste nutrient recovery. Through the biological labour of the larvae, these agents perform a constitutive role, actively "reconfiguring the landscape of capitalism" into the nonhuman world (Braun 2008, 669).

When the inspiration from tubercles on whale flippers was used to radically redesign wind turbines and their aerodynamic efficiencies, the whale was not violently captured to work for humans. However, AgriProtein does not simply harness the intellect of the lifeform, it uses biomimical innovation to commodify and enclose the labour power of its nonhuman agents on an unprecedented scale, both with respect to the sheer number of agents it marshals and the degree of its penetration into non-traditional forms of non-human labour. It is difficult to take issue with biomimicry's underlying intentions and promise, although as nonhuman work is rendered quantifiable it is made "complicit with the structures of dominance over nature that it seeks to overcome" (Fisch 2017, 804). Biological processes under this newly emergent form of biomimicry are not simply "recalcitrant", rather they play an active role in forging new capitalist agents as the insect becomes meshed into new rhythms of industrial production (Braun 2008, 679). As insect labourers are put to work, they require management, synchronisation and training similar to that of any human employee. I do not go into how BSF are trained in this article, but it is another key process in AgriProtein's factories.

\section{Synchronising the Insect with the Pace of Industrial Production}

As I push the trolley of insect grids out of the relative calm of the breeding room, I consider the trajectories of the four kilograms of eggs and the larvae that will hatch from these in the coming days. In nature hatching is a stochastic process, one that scientists at the factory cannot predict. However, the temporal synchronisation of nature, machinery and labour is a fundamental factor in ensuring the viability of an industrial insect farming 
operation. If larvae hatch over their natural seven-day period and are placed in the waste bins at different ages, it would be impossible to create a standardised feeding density and ensure the efficient bioconversion of waste. The company's engineers have therefore devised an incredibly detailed hatching system, where the larvae that hatch on each individual day are collected beneath the 3076 egg grids. This allows early hatching larvae to be naturally selected and preferentially processed. By selecting insects with shorter lifecycles, the larval stage of AgriProtein's BSF has been reduced from fourteen to nine days. Each managed broodstock cycle reduces the insect's larval period making the conversion of waste into value product more temporally efficient.

As homogenously aged larvae are simultaneously brought into the production stage of the insect rearing process, this allows biological events to be synchronised with the availability of the factory's capital-intensive production assets. The hour-old larvae are collected beneath the hatching system and taken into the 'nursery' before they meet their eventual food source. After five days in the nursery being attended to by a dedicated biology team, the larvae enter a robotically controlled phase of production. Larvae bins are loaded onto a conveyor belt that transports them to the main production area of the factory. I stand next to the operator James, who oversees the integration of the waste supply and nursery larvae. Under his watchful eye, the robot loads moisture rich substrate siphoned from two 30,000 litre silos at the end of the organic waste processing area into a fresh pallet. Wriggling, five-day old nursery reared larvae are ready to start work, they are collected from the conveyor belt by the robot and tipped onto their 'larvae lunch'. As the robot drops the larvae onto their food source the bioconversion of waste is initiated. The ability of this particular colony to efficiently process this volume of waste represents a noteworthy optimisation of nature: "Just $1 \mathrm{~g}$ of fly eggs will process and consume $45 \mathrm{~kg}$ of waste; in the wild due to mortality rates this is under 4kgs" (AgriProtein 2017). Larvae will consume many thousands of times their weight in 'larvae lunch' (figure 5), as they grow out under optimal climatic conditions. In under nine days these larvae will transform themselves from tiny eggs, almost invisible to the human eye, into fully grown insect larvae ready for harvesting.

As the larvae continue to mature, they become a valuable source of protein and oil, fed on the waste they decompose. To create a homogenous protein product, harvesting must take place at a scientifically precise life stage. The insects' biological rhythm must be synchronised with the processing ability of this final stage of production. Ninety five per cent of the larvae will be harvested whilst five per cent will follow a separate process to pupate into flies. They will become the breeding stock for the next generation of selectively bred insects.

Nature in the fly factory is constantly being reproduced 'anew', as the reproductive rhythm of the insect is amplified and morphed into an industrial rhythm. All aspects of the insect's life cycle are recreated to enable the amalgamation of waste streams, human work shifts and robotic labour at specific points during the 24hour operation of the factory. The hatching, feeding and processing requirements of the insect are biologically controlled by altering climatic conditions in the factory. Temperature and humidity control are key variables that enable the development of larvae to be inhibited or advanced. In the grow out area, larvae can be cooled to delay growth and allow processing at particular times to prevent production bottlenecks. These larvae logistics are biologically possible, due to the precise biomimetic control of the BSF that occurs at all stages of the insect rearing process.

\section{A Biomimetic Coming}

As AgriProtein's biomimetic technologies artificially reconstruct the insect through material and temporal reorganisations a new nature is produced - one which becomes subject to a regime of private property enclosures. Throughout history, legal constructs have enabled humans to claim rights over nature. These acts, consistent with the law of 'takings', are "intrinsically violent" and produce highly consequential spatial geographies (Blomley 2003, 121). Historically, such acts of 


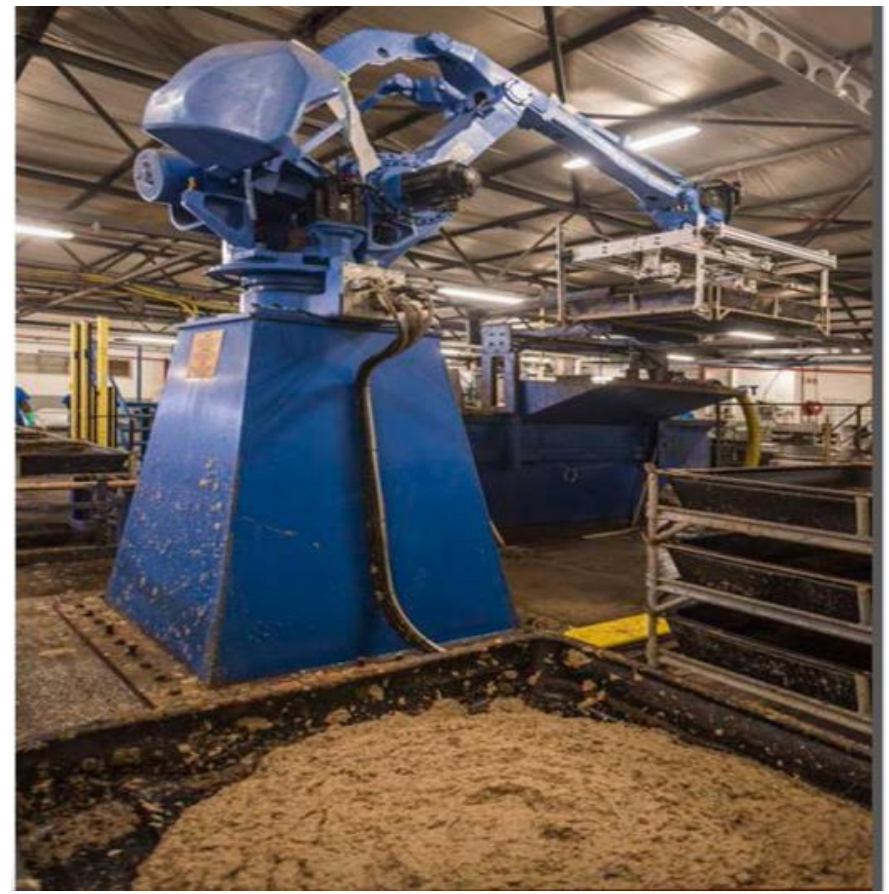

Figure 5. Robotic co-ordination at the twenty-four-hour canteen. Larvae lunch is pumped from two silos in the waste processing plant to meet the larvae recyclers who initiate the bio-conversion process. Photo: Charlie Drew.

material violence used barbed wire to police boundaries around private land (Blomley, 2003). This section will question what it means to police artificially constructed boundaries around nature and analyse the inherently violent act of dispossession and enclosure that seeks to circumscribe the natural world. The act of patenting "confers a temporary monopoly on the holder" subject to that invention being made available in the public domain Jasanoff 2012, 165). Intellectual property laws, however, were not written with biotechnology in mind; "the assumption under Western legal systems is that nature is the common property of human kind" (Jasanoff, 157).

The enclosure of the insect through the act of patenting its intellectual property "enables the realms of biological reproduction and capital accumulation" to move closer together (Cooper 2008, 3). The privatisation of this genetic strain of the fly signals a new form of 'bio-accumulation' that is premised upon the commodification of nature (McCarthy 2004, 329). Efforts to enclose the fly are not just limited to the synchronisation of the larvae's life cycle, selective breeding or its reproductive manipulation. These enclosures developed in the insect factory seek to uncover and subsequently privatise new territorial domains, as they enter the micro-spaces of the insect's genome. These enclosures are not initiated by the biology managers, rather they originate from the board room and are driven by $a$ further constellation of capitalist forces.

On the penultimate day of my research in Cape Town I was invited to observe a meeting between company executives and an external patenting consultant. In the emerging insect farming industry, establishing and securing a dominant market position is a fundamental objective for the company's investors. Biotechnology companies can capture considerable value from property patents as artificially constructed barriers to market entry that constrict competition (Labban 2014).

AgriProtein's selectively bred fly has particular beneficial traits for industrial production; the company is now mapping the genome of this insect to prospect for these phenotypes. These observable traits can be directly attributed to a mapped genetic phenotype. This process of 'bio-prospecting' involves proving the causality between genetic DNA expressions and insect attributes, resulting in the "vertical integration of nature into capital" (Smith 2007, 33). This phase of bioaccumulation moves beyond scouring nature for organisms to enclose and towards securing exclusive rights over "the nature of life" (Prudham 2007, 411). If a part of the natural world can be proved to be a "fiction of autonomous invention" it risks producing a humanised nature that is "financialised all the way up" (Smith 2007, 33). Successful approval of international patents will allow AgriProtein to lay claim to their own strain of the BSF and identify genetic ownership of this selectively bred sub-species.

The granting of property rights over new biotechnologies is subject to increasing contestation and critique from social scientists who consider the "alienation of ecological production" as a new form of bioaccumulation that is emerging through "extra-economic means" (Prudham 2007). Patents over "genomic expressions amount to de facto patents over whole organisms" and consolidate private claims to altered organisms as patentable inventions (Prudham, 407). These patents raise important questions about what is considered 'manufactured' or a composition of nature's 
intellect. They point towards the construction of a 'socio-nature' driven by neoliberal reconfigurations of nonhuman life (Whatmore 2002). The object of the patent claim is set aside from nature, "corralling a part of it" as it is labelled a product of human invention (Jasanoff 2012, 157). Where these patents are granted and 'genetic reductionism' is legally sanctioned, this has considerable implications for the concept of universal natures (McAfee 2003).

Life patenting legitimises what De Angelis $(2004,81)$ terms 'biopiracy' as the privatisation of nature's knowledge that has been collectively produced by generations of 'experimenters' over 3.8 billion years is severed from the commons. Whilst the notion of 'biopiracy' is frequently associated with violence towards and the appropriation of knowledge from indigenous communities, this form of oppression can be seen to operate in new directions within the biomimicry discourse. Although the subject of the agent differs, there is a structural analogy between these two realms and expressions of violence. This legally enshrined act of dispossession has a stark temporality to it. Nature's expertise, which has been accumulated over the long term, is appropriated from the natural realm in a very short enactment of legal violence.

AgriProtein's attempt to privatise intellectual property does not stop at the level of the organism that they have genetically selected. The company has also patented the specific wavelength of light that causes mating and its application in mass insect rearing. This represents a move beyond the enclosure of privately constructed organisms towards what McCarthy $(2004,335)$ labels as the privatisation of "ecosystem services and environmental conditions". Under continual acts of 'bioprospecting' the company is "dispossessing nature" as it orchestrates new methods to scour the natural world for defensible property rights (Smith 2007, 31). The active removal of natural intellect from the domain of nature into the domain of human capitalism increases the divide between these two realms (Jasanoff, 2012). This act of "ontological surgery" legally constructs and demarcates aspects of life which can be owned (Jasanoff, 161). As the gradual legal erosion of nature prevails and the law produces "more definitive ontological settlements" it is easy to overlook the environmental merits of these technologies in the face of this capitalist onslaught Jasanoff, 163).

Enclosing the insect through intellectual and legal capture raises considerable ethical concerns over the role nonhuman life plays in facilitating bioaccumulation. However, Labban (2014) emphasises the need to positively acknowledge these contributions to the 'bioeconomy'. Recognising the beneficial "encounter between productive practices and nonhuman organisms" does not negate the political concerns that are associated with these technologies (Labban, 561). Ethical contradictions remain evident on the factory floor. A biomimetic future that subjects the 'pesky fly' to a form of violence may, however, be a considerably more sustainable trajectory than overfishing which currently threatens to eliminate tracts of marine life from our oceans.

As I stand at the processing mill, protein-rich ground larvae flow out of the 'bio-separator' whilst refined 'MagOil ${ }^{\mathrm{TM}}$ ' and 'MagSoil ${ }^{\mathrm{TM}}$ ' are also extracted during the production process. I consider the relative violence of harvesting insects in comparison to traditional forms of protein extraction that pillage the oceans for fishmeal, a protein that is decimating pelagic fish and krill stocks. Insect farming represents a paradigm shift in protein production towards a more sustainable form of urban waste nutrient recycling. Each tonne of MagMeal ${ }^{\mathrm{TM}}$ produced prevents three tonnes of fish from being removed from the ocean (AgriProtein 2017). As pelagic fish stocks decline, fishing vessels must trawl further and deeper, consuming double the quantity of diesel whilst using more exploitative nets in order to return the same volume of catch as they did a decade earlier (AgriProtein, 2017). In stark contrast, AgriProtein's technology is giving rise to a more proximal urban production of protein from insect farms that are being integrated into the fabric of the city. The ability to process waste, create protein and biofuel closer to its eventual point of consumption has an estimated environmental cost saving of $£ 1,500$ per tonne produced (AgriProtein, 2017). This technology seemingly fits with greater ease into the rhythm of urban ecology in juxtaposition to large scale ocean trawling that drives the competing 
economic and environmental geography. Having considered the temporal and spatial rhythms of the insect factory, AgriProtein's technology is driving a considerable and scalable geography that seeks to redefine how urban ecologies are envisaged.

AgriProtein has been commissioned to provide an organic waste solution for NEOM the new Saudi Arabian megacity to be constructed in the Kingdom's north-western seaboard. Multiple factories will be integrated into the city's unconstrained vision for sustainable urban civilisation. This process will create links between the natural and urban worlds as the processing of waste and the production of protein becomes integral to the structural design of cities. This technology will not stop waste from being produced, rather it includes a system to re-purpose it within new geographies of the urban economy. Biomimical technologies enacted in this way can shift the ontology of a city as they foster more collaborative urban design strategies that integrate with nature (Taylor-Buck, 2012). This ontology can support the planning of urban scale biomimical infrastructures that deliver a "living city" model (Taylor-Buck, 2012, 120). This urban ecosystem model envisages cities as natural entities that are designed and managed to solve urban resource constraints. They produce a closed loop urban ecosystem where all waste is considered as a commodity to be repurposed and thus re-valorised within the confines of the urban framework.

\section{Conclusion}

Vuyo and I load five tonnes of ground packaged MagMeal $^{\mathrm{TM}}$ into a delivery truck and begin the short drive across Philippi township to the market leader in South African animal feed. This brief journey allows me to contemplate what this empirical case reveals about changing waste, protein and commodity circuits in the global economy. Somewhere within truckloads like these were the leftovers of my lunch, now measured and packaged for sale. The larvae lunch consumed by AgriProtein's insect colony formed part of the Capetonian's leftovers a couple of weeks ago has now been transitioned into a product that monogastric farmers are scrambling to get their hands on. Khalla meets us at the gate to take delivery of a sustainable insect feed that his chickens would forage naturally for in the wild. This protein which is made without artificial and anti-biotic additives is the result of many years of investigative and pro-active biomimical application. Whilst this upcycled commodity diverts waste from landfill, it cannot afford to deflect attention away from the underlying ethical concerns with this technology. Like many similar design strategies that draw inspiration from nature, biomimical technologies are forever "troubled by a relationship to an original" (Fisch 2010, 817). This concern arises from a scientific movement, initially inspired by nature, that contorts it into a mimicry predicated upon the securitisation of nonhuman agents for their ability to reproduce and perform functions that serve capital. A biomimetic discipline emerges that is distanced from its imitative relationship with the natural world and produces technologies that are no longer "categorisable as belonging to nature" (Fisch 2010, 818). Benyus' initial vision for the biomimicry discipline included the "total cessation of human dependence on the reproductive capacities of natural organisms" (Fisch 2010, 814). This conception has become thwarted by a technology that presses the boundaries of the biomimicry discourse in new ways. AgriProtein's application of biomimicry is contingent on "producing biocapital by harnessing the regenerative power of organisms" (Helmriech 2009). This technology 'bio- utilises' nonhuman nature by manipulating the reproductive rhythm of the insect. It subjects the lifeform it encloses to an intrinsically violent technology, whilst seeking to replace an exploitative and environmentally destructive market system that threatens the future of our oceans.

Biomimical technologies are concerned with problem of who has the authoritative power "to issue evaluative judgements" about the relative ethics of each particular application (Fisch 2010, 817). This research highlights that the political and ethical tensions for this particular case of industrial biomimicry remain unresolved and leave us with a challenging set of practical considerations. On the factory floor, the market avoids this tension by overlooking the issues of violence and exploitation, political ecologists however must consider the relative moral coherence of each individual case. Biomimicry's 
ethical dilemma can be considered within the following dichotomy. On the one hand this scientific movement produces a "bio-inclusive ethic" through a more morally coherent and sustainable mode of production (Matthews 2011, 380). As humans resituate themselves within the natural realm, to redesign exploitative industrial modes of production, they can be seen to give voice to 'the parliament of species' (Benyus 1997). On the other hand, during this restitution, the collaborative dialogue between humans and nonhumans is superseded by technologies of enclosure that produce a "new nature of our own design" (Matthews 2011, 381). The use of biomimicry with anthropocentric intent wrenches open the boundaries between humans and the natural world that it originally sought to repair, producing a nature that is "exclusively human in its provenance and constituency" (Matthews 2011, 381). As I ponder these potential ethical choice sets our global population continues to produce exponential quantities of potential larvae lunch. This represents an opportunity to reimagine global waste and protein markets - a challenge which AgriProtein's insect colony are buzzing about.

\section{Acknowledgements}

I would like to thank the 8.4 billion larvae at the AgriProtein factory in Cape Town, South Africa, who were kind enough to let me observe and research them. I would also like to extend my gratitude to my fantastic supervisor Jeremy Schmidt who was far more willing than the larvae to offer his time, support and encouragement for the research and write-up of this project. 


\section{References}

Bennett, Jane. 2010. Vibrant Matter: A Political Ecology of Things. Durham: Duke University Press.

Benyus, Janine. 1997. Biomimicry. New York: William Morrow.

Blomley, Nicholas. 2003. "Law, Property, and the Geography of Violence: The Frontier, the Survey, and the Grid." Annals of the Association of American Geographers, 93(1): 121-41.

Braun, Bruce. 2008. "Environmental Issues: Inventive Life." Progress in Human Geography 32(5): 667-79.

Buitrago, Alvaro Sevilla 2015. “Capitalist formations of enclosure: Space and the extinction of the commons." Antipode 47(4): 9991020.

Castree, Noel. 2002. "False antitheses? Marxism, nature and actornetworks." Antipode: A Radical Journal of Geography 34(1): 11146.

Cooper, Melinda. 2008. Life as Surp/us: Biotechnology and Capitalism in the Neoliberal Era. Seattle: University of Washington Press.

De Angelis, Massimo. 2004). "Separating the Doing and the Deed: Capital and the Continuous Character of Enclosures," Historical Materialism 12(2): 57-87.

Dyer-Witheford, N. (1999). Cyber-Marx. Cycles and Circuits of Struggle in High-Technology Capitalism. Urbana/Chicago: University of Illinois Press.

Fisch, Michael. 2017. "The Nature of Biomimicry: Toward a Novel Technological Culture." Science, Technology, and Human Values 42(5): 795-821.

Food and Agriculture Organization of the United Nations (FAO) 2008. The State of Food Insecurity in the World 2008: High Food Prices and Food Security-Threats and Opportunities. Available at: http:// www.fao.org/3/a-i6030e.pdf (Accessed February 28, 2018).

Foucault, Michel. Discipline and Punish. London: Penguin Books.

Gidwani, Vinay and Reddy, Rajyashree. 2011. "The afterlives of "waste": Notes from India for a minor history of capitalist surplus." Antipode 43(5): 1625-1658.

Goldstein, Jesse \& Johnson, Elizabeth. 2015. "Biomimicry: New natures, new enclosures." Theory, Culture \& Society 32(1): 61-81. 
Goldstein, Jesse. 2012. "Terra Economica: Waste and the Production of Enclosed Nature." Antipode 41(2): 357-375.

Gregson, Nicky. \& Crang, Mike. 2010. “Materiality and waste: inorganic vitality in a networked world." Environment and Planning A 42(2): 1026-32.

Guest, Greg, Namey, Emily, and Mitchell, Marilyn. 2012. Collecting Qualitative Data: A Field Manual for Applied Research. Thousand Oaks, California: Sage Publishing.

Haraway, Donna. 2008. When Species Meet. Minneapolis: University of Minnesota Press.

Harvey, David. 1996. Justice, Nature and the Geography of Difference. Oxford: Blackwell.

Harvey, Neil. 2009. "What's Good for Life Wins: The Biomimicry Scientific Revolution", Bioneers Radio Series Podcast, available at: https://itunes.apple.com/us/podcast/bioneers- revolution-fromheart-nature-bioneers-radio/id965064938?mt=2 (Accessed 1 December, 2017).

Helmreich, Stefan. 2009. Alien Ocean: Anthropological Voyages in Microbial Seas. California: University of California Press.

Jasanoff, Sheila. 2012. "Taking Life: Private Rights in Public Nature," in K. Rajan (Ed.), Lively Capital: Biotechnologies, Ethics, and Governance in Global Markets. Durham: Duke University Press.

Johnson, Elizabeth and Goldstein, Jesse. 2015. "Biomimetic futures: Life, death, and the enclosure of a more-than-human intellect." Annals of the Association of American Geographers 105(2): 387396.

Johnson, Elizabeth 2010. “Reinventing biological life, reinventing 'the human." Ephemera 10(2): 177-193.

Katz, Cindy. 1998. "Whose Nature, Whose Culture?" In Braun, Bruce, and Castree, Noel (eds), Remaking Reality: Nature at the Millenium, London: Routledge.

Khan, Amina. 2017. Adapt: How We Can Learn from Nature's Strangest Inventions. London: Atlantic Books.

Kirksey, Eben and Helmreich, Stefan. 2010, "The Emergence of Multispecies Ethnography." Cultural Anthropology 25(4): 545-576. 
Kosek, Jake. 2010. "Ecologies of Empire: On the New Uses of the Honeybee." Cultural Anthropology 25(4): 650-678.

Labban, Mazen. 2014 “Deterritorializing extraction: Bioaccumulation and the planetary mine." Annals of the Association of American Geographers 104(3): 560-76.

Lempriere, Molly. 2017. “Could biomimicry revolutionise renewable energy?" Power Technology, http://www.power-technology.com/ features/featurecould-biomimicry- revolutionise-renewableenergy-5796192/ (Accessed January 23, 2018).

Mathews, Freya 2011. "Towards a deeper philosophy of biomimicry." Organization \& Environment 24(4): 364-87.

McAfee, Kathleen. 2003. "Neoliberalism on the molecular scale: Economic and genetic reductionism in biotechnology battles", Geoforum 34(2): 203-219.

McCarthy, James. 2004. "Privatizing conditions of production: trade agreements as neoliberal environmental governance." Geoforum 35(3): 327-41.

Mitchell, Timothy. 2002. Rule of Experts: Egypt, Techno-Politics, Modernity. Berkeley: University of California Press.

Perkins, Harold. 2007. "Ecologies of actor-networks and (non) social labor within the urban political economies of nature." Geoforum 38(6): 1152-62.

Prudham, Scott. 2012. Knock on Wood: Nature as Commodity in Douglas-Fir Country. New York: Routledge.

Prudham, Scott. 2007. "The Fictions of Autonomous Invention: Accumulation by Dispossession, Commodification and Life Patents in Canada." Antipode 39(3): 406-429.

Smith, Neil. 2009. "Nature as accumulation strategy." Socialist Register 43(3): 1-21.

Taylor Buck, Nick. 2017. “The Art of Imitating Life: The Potential Contribution of Biomimicry in Shaping the Future of our Cities."

Environment and Planning B: Urban Analytics and City Science 44 (1): 120-140.

Whatmore, Sarah. 2002. Hybrid Geographies: Natures Cultures Spaces. Thousand Oaks, California: Sage Publishing. 